\title{
Lynch 2 Syndrome
}

National Cancer Institute

\section{Source}

National Cancer Institute. Lynch 2 Syndrome. NCI Thesaurus. Code C6726.

A rare genetic neoplastic syndrome with an autosomal dominant pattern of inheritance but incomplete penetrance. It is associated with an inherited risk for malignancy, in particular, colorectal, endometrial or gastric carcinoma. It is caused by mutations in one of the mismatch repair genes: MSH2, MLH1, MSH6 or PMS2. It usually manifests at age 50 or younger with multiple synchronous or metachronous proximal colonic or extracolonic cancers. Clinical course is rapidly progressive. Prognosis is variable with high risk for development of gastrointestinal, reproductive or urinary tract cancer. However, survival is significantly better than non-HNPCC carcinomas of equivalent stage. 